\title{
The Lived Experience of Parents of Children with Sickle Cell Disease: A Qualitative Study
}

\author{
Raeda M. Abu Ali' ${ }^{1}$ Nadin M. Abdel Razeq ${ }^{2 *}$ \\ ${ }^{1}$ Department of Allied Health Sciences, Al-Salt College for Human Sciences, Al-Balqa’ Applied University, Al-Salt, Jordan \\ ${ }^{2}$ Department of Maternal and Child Health Nursing, School of Nursing, The University of Jordan, Amman, Jordan \\ Email:raeda17@yahoo.com,raedamabuali@gmail.com, *nmians@yahoo.com, ^n.abdelrazeq@ju.edu.jo
}

How to cite this paper: Ali, R.M.A. and Razeq, N.M.A. (2017) The Lived Experience of Parents of Children with Sickle Cell Disease: A Qualitative Study. Open Journal of Nursing, 7, 1348-1364.

https://doi.org/10.4236/ojn.2017.711097

Received: October 14, 2017

Accepted: November 27, 2017

Published: November 30, 2017

Copyright $\odot 2017$ by authors and Scientific Research Publishing Inc. This work is licensed under the Creative Commons Attribution International License (CC BY 4.0).

http://creativecommons.org/licenses/by/4.0/

\begin{abstract}
Background: Sickle cell disease is an inherited hematological disorder that inflects complex demands on the lives of the children and their families. Aim: To describe the lived experience and everyday strains of parents of sickle cell disease children. Methods: A descriptive qualitative approach was used. Data were collected using face-to-face interviews with 11 parents of children with sickle cell disease in Jordan. Results: Emerged themes were: 1) the catastrophe, which summarized the effect of the confirmed diagnosis of sickle cell disease in the children on the parents, 2) parenting hardships, which highlighted aspects of parents' reported challenges and needs while caring for their sickle cell disease children, and 3) networking and support, which described patterns of support that parents sought to fulfil needs for support and information. Conclusions: Healthcare providers should carefully assess the complex caregiving demands and altered family dynamics that the parents of children with sickle cell disease face. Parents' psychosocial health issues should be essential elements in planned care of children with sickle cell disease. Nursing and social work professionals can play a vital role in developing and implementing a comprehensive model of care with community-based approach and strategies to maximize the wellbeing of sickle cell disease children and their parents.
\end{abstract}

\section{Keywords}

Sickle Cell Disease, Chronic Illnesses, Parents, Caregivers, Children, Jordan

\section{Introduction}

Sickle cell disease (SCD) is a life-threatening inherited hematological disorder. An estimated 5,788,700 neonates worldwide were affected by SCD in 2010 [1]. Abnormal sickle-shaped erythrocytes cause intermittent and recurring complications leading to substantial morbidity and early mortality [2]. Individuals with 
SCD, including children, require frequent hospital care for long-term blood transfusion therapy and management of acute physical complications. Patients with SCD suffer from numerous physical conditions such as hemolytic anemia, acute vasoocclusion causing excruciating pain, embolisms in various locations throughout the body, and eventually death [3]. Psychological health challenges, such as sleep disturbances, negative body satisfaction, fatigue, anxiety, depression, and attempted suicide have been reported regarding youth with SCD [4] [5] [6] [7]. Bone marrow transplantation can be curative; however, it is rarely used because of its perceived toxicity and the lack of suitable marrow donors [8]. Therefore, the treatment is typically symptomatic and preventive. These treatments include long-term transfusion therapy, hydration, hydroxyurea therapy, and pain management [3] [9]. All of these illness and treatment related issues result in multiple challenges and demands on parents of children with SCD, as those parents are often the primary caregivers.

SCD in children inflect high physical, social, and psychological cost on parents' caregivers. A recent systematic review showed that parenting stress is significantly greater among caregivers of children with chronic illnesses than it is among caregivers of healthy children [10]. However, evidence concerning the lived experience and everyday strains of parents who care for children with SCD is relatively rare. The few studies done on the topic have shown that caring for a child with SCD is both stressful and demanding for parents. Parents of children with SCD have reported negative impacts of the disease on their emotional health [6] [11] and on their personal lives, in areas such as job performance, employability, and socioeconomic status [12] [13]. Past studies have also shown a negative impact of the disease on family dynamics, such as difficulty in maintaining family relationships, fulfilling family commitments, and meeting the needs of other family members [12] [14] [15]. While most past studies on parents taking care of SCD are performed in African or well-resourced countries, studies of the topic in the Middle East are limited. Child health care providers need to provide individualized holistic care for the children, as well as their parents, within a culturally sensitive context.

There is a need to understand further the nature of the everyday experience of parents who have children with SCD in a Middle Eastern society. By describing the parenting experience of SCD children, the health care needs of both the children and their families can be understood and met more effectively, and so the health care practice and the overall quality of life of this population can be improved. Therefore, the lived experience and everyday strains of a sample of parents from Jordan caring for children with SCD was explored in depth and comprehensively described in this paper.

\section{Methods}

\subsection{Design}

A descriptive qualitative approach was used to achieve an understanding of the everyday experience of parents who care for children with sickle cell disease while 
taking into account the sociocultural traditions that give those experiences their unique meaning.

\subsection{Participant Selection}

Parents of offspring with SCD who were under the age of 18 , and who presented at a blood disease centre in a major public hospital in Jordan for having regular blood transfusions and/or treatment of SCD complications were eligible to participate. In order to capture a broad variety of participants' experiences, there were no exclusion criteria based on the parents and/or children's demographic data and children's SCD genotype. Sample size was determined based on the richness of the data. Both investigators were satisfied that no new patterns of information were emerging after interviewing 11 parent caregivers. The first researcher invited parents to participate between October and December of 2016. All parents that were approached showed interest in participating; each decision was based solely on freewill, with no incentives being provided. No participants withdrew their consents following the interviews.

\subsection{Data Collection}

The Scientific Committee at the School of Nursing, University of Jordan, and the Institution Review Board (IRB) at the Ministry of Health, Jordan, reviewed and approved the study. Prior to the interviews, the interviewer explained participants' rights to the parents, including the matters of confidentiality and the right to decline to answer any given question if the participant so wished. All participants consented to take part in the study and to use audio recording prior to the interviews.

Semi-structured face-to-face interviews were used for data collection. Participants were given the choice to suggest the time and location of the interviews. Accordingly, all interviews were conducted at the bedside, with the door or curtains closed. The first researcher interviewed all of the participants; the researcher and participants sitting face to face with the audio-recorder placed in the middle. An interview took 20 to 30 minutes. A relationship was established prior to the interviews through general questions about the children's condition and the parents' overall satisfaction with the care provided. The demographic characteristics of the children and their parents were obtained during the interviews. No data were obtained from the charts per the protocol of the study. The semi-structured interviews started with predetermined general questions to generate a narrative discussion on a timeline, from the time of the first diagnosis of the disease in the children to the everyday management of SDC and hospital experience. The interviewer narrowed the questions towards more specific questions, based on the flow of the discussion with the parents; encouraging the parents to express feelings and underlying meanings related to their experiences.

\subsection{Data Analysis}

Conversations with the parents were transcribed verbatim with the participants' 
names censored and replaced by identification numbers. The data were verified and analyzed by two researchers independently; the results were compared and disagreements were discussed. Thematic analysis at the semantic level was applied [16]; data were grouped into broad units, and then categories, subcategories, and themes were generated accordingly. Participants' quotes were linked to the main findings as appropriate. Descriptive statistics were used to summarize the participants and children-related demographics information.

\section{Results}

\subsection{Description of Sample}

The 11 participants consisted of eight mothers and three fathers. All participants and their spouses were carriers to the SCD trait and the disease affected none; however, two participants had family relatives affected by SCD other than their children. Two of the three fathers were manual laborers and one was a teacher in a public school. All of the mothers were homemakers. Table 1 includes more details on the parents' socio-demographic characteristics. The ages of the children at the time of interviews ranged from 4 to 17 years, with $50 \%$ having splenectomy and only two using hydroxyurea at home.

\subsection{Thematic Analysis}

Three themes emerged from the interview discussions about parenting children with SCD: 1) the catastrophe, 2) hardship of parenting children with SCD, and 3) networking and support.

Table 1. Sample characteristics.

\begin{tabular}{lcc}
\hline & F (\%) & M (min-max) \\
\hline $\begin{array}{l}\text { Age (years) } \\
\text { First degree cousins involved in }\end{array}$ & $7(26-59)$ \\
consanguineous marriages & \\
Mean monthly income (US Dollars) & $11(100)$ \\
$\qquad 700$ & $0(0.0)$ \\
$\geq 700$ & \\
Highest education level & $1(9.1)$ \\
$\quad$ Bachler degree & $1(9.1)$ \\
High school & $2(18.2)$ \\
Secondary school & $6(54.6)$ \\
Elementary school & $1(9.1)$ \\
No education & \\
1 & $6(54.6)$ \\
2 - 3 & $5(45.4)$ \\
Number of children with sickle cell disease in the family & $0(0.0)$ \\
&
\end{tabular}


Theme 1: the catastrophe

The confirmed diagnosis of SCD in the children was catastrophic for the parents. The diagnosis was normally made when parents sought medical attention for general symptoms, indicating SCD complications. Children were diagnosed between the ages of 4 months and 4 years, with the diagnosis being made most commonly around age of one-year. The most common pre-diagnosis symptoms were hypoactivity, poor feeding, and failure to thrive, jaundice, sever pain, and fever. Prior to diagnosis, the laboratory tests confirmed severe anemia in children with hemoglobin levels as low as 4 and $6 \mathrm{mg} / \mathrm{dl}$ (normal $12-15 \mathrm{mg} / \mathrm{dl}$ ) according to the participants. The anemia eventually led to a series of clinical investigations culminating in the initial diagnosis of SCD.

None of the interviewed parents sought medical advice before the symptoms of the disease's complications appeared, even when there was a history of other siblings or relatives with SCD in the family. Additionally, parents reported never knowing that they were carriers of the disease trait, and therefore they never sought screening prior to their children diagnosis. The parents only knew that they were carriers of the SCD gene after their children's first diagnosis of SCD:

"We had no idea, not even any of our family members knew that we carry the trait" (Mother \#2).

Parents reported the severe emotional impact of learning about the SCD diagnosis in their children. The news was difficult for them and their families. Extreme "shock," "surprise," "frustration," "hurting," and "sadness" were just a few of the terms that parents used to describe their emotions upon receiving the SCD diagnosis in their children. One mother described her experience of receiving the diagnosis as follows:

"It was a feeling that is beyond description. I was very distressed, very, very distressed. It was not just me; the whole family was... it [the news] was hard on all of us." (Mother \#2)

The parents were asked in the interviews what would they do if they witnessed a couple who were engaged to be married and both were confirmed to carry the SCD trait. Parents' responses were consistent: all parents agreed that the marriage should not happen, in order to avoid the extreme agony and "life-long" hardship that comes along with having a child with SCD. The parents described that SCD caused "unbearable suffering" to their children's lives, themselves, and their entire family:

"If it was in my hands to stop it, I would do so for the baby not to suffer. The suffering is not limited to the baby however, but to the father and mother as well. We all suffer. If I was able to offer advice, I would advise not to go on with the marriage." (Father \#6).

It was repeated consistently in participants' reports that they would not wish the suffering and helplessness that they have felt to be inflicted on anyone else:

"Because I don't like anyone to suffer the way I do. I see my son suffering and I feel helpless... This is the hardest experience." (Mother \#2) 
Self-blaming and regret were obvious in the overall conversations with the participants. One particular participant expressed a wish that she could have changed her marriage decisions if she knew in the past what she knows now:

"There was not such a test in earlier days... Otherwise, I would not have gotten married to him [her spouse]" (Mother \#7)

Parents in the interviews made efforts to distinguish between being hurt by the diagnosis, but also refusing to "not accept the child," as they considered the child as "God s giving." All participants reported spiritual values in every conversation about the emotional impact of the diagnosis. Parents often viewed having a child with SCD as a test from God that they should not complain about. In fact, a mother directly asked God's forgiveness when she called having a child with SCD a calamity:

"It is a curse, oh Allah almighty forgive me, thank God for everything" (Mother \#5)

Rather, the parents repeatedly reported submissively giving in to God's will, and thanking God for His choice, despite the hardship and emotional difficulty that they felt when they received the diagnosis:

"It was a shock, but thank God for all He has given. As it is said, anything from God is welcomed and we thank Him for it and tolerate our sorrows and sufferings." (Father\#6)

Despite the spiritual meanings that parents associated with the diagnosis of having a child with SCD, the diagnosis shocked the parents and caused great negative emotional impact on the whole family. This was applicable not only to the parents who had a history of SCD among their extended family, but also to those who did not have such a history.

Theme 2: parenting hardship

After their children's diagnosis with SCD, parents had to face the reality of the illness, and to manage everyday life while caring for their children with SCD. Hardship, struggle, and difficulty were the characteristics of life that parents described when caring for children with SCD. Children's pain during vasoocclusive attacks was the outmost source of parents' stress. Witnessing their children suffering pain of extreme intensity during a vasoocclusive crisis inflicted great emotional distress and complex caring demands on both the parents and the family overall.

Seven parents reported that severe pain-crises requiring medical attention occurred at least once to twice per month. Parents reported that these episodes could require an average of four to five, and up to 10 days of staying in the hospital. A mother described the pain intensity in her child as follows:

"The severity of pain is $100 \%$. It is so, so much pain... a very severe pain, meaning three days of screaming in pain and not being able to sleep because of pain." (Mother \#5)

More frequent but mild pain was also reported:

"No day passes without my daughter complaining about pain, especially in the winter, she suffers pain, but mild pain as she says." (Mother \#2) 
The unpredictability of painful SCD attacks in terms of intensity, frequency, and body location added extra stress to parents; they were living "on edge" and were in a state of constant anticipation between their child's pain attacks. Parents suffered extreme sadness, anxiety, and helplessness during these painful crises:

"The suffering is hard; to watch your son in pain and not be able to do anything is so hard. I do not want anyone to suffer as much I do." (Mother \#2)

Parents expressed literally living their children's pain:

"I am in pain when I am next to him! You do not want to see his brothers and sisters really suffering with him. If your son is feeling pain, then you feel the same." (Father \#3)

Pain-crises were primarily managed in hospitals, rather than at home. Home treatment of the painful episodes was minimal and was done so with the purpose of soothing pain until children could be brought to the hospital. At the hospital, parents preferred that children with pain crises be seen at the blood disease centre during working hours, rather than through the emergency room:

"We give him analgesics to ease the pain in addition to juice and water, so that his blood can continue moving. We wait for one or two hours, then we take him to hospital." (Mother \#10)

"I provide her with liquids, keep her warm, asleep, and less active. I take care of her and keep her close to me, and if the attack happens at night, I stay at her side until morning, then I take her to the hospital." (Mother \#1)

Non-steroidal anti-inflammatory drugs (NSAIDs) were the medications most commonly reported by parents to be given both at home and at the hospital. NSAIDs were given orally at home and intravenously at the hospital. The participants rarely mentioned opiates for pain management at home, or at the hospital.

Another focus that comprised a considerable share of the conversation with parents was the children's frequent hospital visits for blood transfusions; parents often referred to the blood transfusion days as "blood-days." Blood was administered for the treatment of the painful crises and anemia in the children every 20 days to every year; children with splenectomy required blood transfusion less often:

"Well, it used to happen every couple of weeks, but when they took out his spleen, blood transfusion frequency depended on his blood count. After this, it changed to be around once a year or year and a half." (Mother \#10).

The blood-day was described as a full day in the hospital, which often began as early as 7 or $8 \mathrm{am}$, and ended 6 to 9 hours later. The routine consisted of a visit to the blood disease centre, or emergency room, where laboratory work, including complete blood count measurements, was performed. Parents would wait for lab results to be released, and then parents and children would visit one of the physicians at the blood disease centre, where the need for a blood transfusion and treatment was determined. If a blood transfusion was ordered, parents reported waiting among the crowds between 3 - 5 hours for blood preparation at 
the blood bank, and then an extra 3 - 4 hours for blood transfusion at the blood disease centre. The parents often delivered the blood units from the blood bank to the blood disease centre by hand, which required around 10 minutes of walking. Although the blood-day consisted of a few predictable steps, it was repeatedly described as laborious, tiring, strenuous, and crowded:

"It is a long exhausting day honestly." (Father \#9)

Frequent hospital visits for their child's treatment, waiting for long hours for blood preparation and transfusion, and postponing other duties, such as work, managing home and caring for other siblings at home, were all strains that participants associated with both the blood-days routine and hospitalization for pain crises treatment. Typically, parents stayed the entire day with their children at the hospital, as doing so was considered by the mothers an expected responsibility of motherhood. As mother\#8 described:

"Mothers would never leave their daughters or sons [when they were in the hospital]. When they need blood, they wait for them. They stay [at the hospital] until their children are done and then leave [the hospital] with them. Certainly a mother would do her best for the sake of her children, especially if they are sick." (Mother \#8)

Not being able to balance the strains of taking care of the SCD child at the hospital and home demands created a sense of insufficiency by the mothers:

"I have often felt that I neglect my home and do not give enough time for the rest of my family because I spend too much time at the hospital." (Mother \#11)

Mothers, in particular, often struggled with leaving young siblings at home. Having someone to care for the siblings during the hospital stays and the blood-days of the children with SCD were difficult to arrange. Their spouses often could not take days off work; therefore, mothers often brought all their preschool-age siblings to the hospital with the SCD children during treatment. This was less of a source of struggle though for older siblings, who went to school and could take care of themselves, while their mothers went to the hospital with the SCD children.

In the case of fathers, wives cared for the young siblings at home. Therefore, for the fathers managing work was a major strain during emergency hospital visits and during blood-days. Fathers often had to take off few hours of their jobs, absences that were sometimes unpaid, to bring their children to the hospital, and to follow-up with lab work and blood-day procedures. While the children were in the care of the medical staff, the father participants often left to go to work, then returning to the hospital after their working day was over:

"I only leave because I have a job at the same time. I leave work to get him to the hospital, then I go back to continue work, and then come back to him." (Father \#9)

The disease placed complex demands and strains on the parents, and the families, as a whole. The parents viewed managing these complex caring demands as a normal and expected part of their parenthood. 
Theme 3: networking and support

Details relating to patterns of networking and support during the frequent hospital admissions of the children appeared in the parents' interviews. Networking took two forms in the family reports: 1) family-family relationships and 2) family-nurse partnerships.

Family-family relationships were the most obvious among mothers. Relationships often emerged between mothers while waiting for their children's treatment during the frequently occurring blood-days. The mothers' reported that the relationships between parents often started by simple questions that compared the conditions and treatments of their children:

"Oh yeah, we both keep asking if our children suffer the same symptoms." (Mother \#2)

Mother \#11 indicated that networking with others in general was something that was sought:

"Well, I ask anyone at the centre if they suffer the same attacks and how often they take blood... I like to know." (Mother \#11)

In fathers, family-family relationships were evident, but less commonly:

"I do not interact with people that much, though there are women who do talk to each other... well I believe most of the women do." (Father\#6)

The Jordanian cultural values about gender segregation appeared obvious in father's narratives about family-family relationships, where networking and interactions usually happen between same genders:

"Some relationships with other men [fathers and young SCD male children] have developed." (Father\#9)

Networking through family-family relationships served many purposes. First, it provided the parent caregivers with a source for exchanging information and it provided the parents with an informal means to understand SCD, its severity, and its treatment:

“... and we have tried to exchange experiences and information to be able to overcome some issues with our children." (Father \#9)

Second, through networking, caregivers provided practical help for each other, especially during the blood-days:

"We assist each other, for example when my child receives blood, the mother of the child in the next bed would keep an eye on my child and call the nurse when the blood was finished, that sort of thing." (Mother \#1)

Finally, networking provided the parents with a sense of peer support and belonging to a group. Father \#9 explained why he only felt comfortable talking to those who had experience with the disease:

"Well, those who understand are those who are related to this disease and the ones who suffer this disease, while others do not. On the contrary, I do not like to go through a discussion with those who do not have the disease, just because they are ignorant and that is it?' (Father \#9)

Blood-days meant spending long hours in the hospital, during which parent 
caregivers reported being involved in providing different types of care to their children. Parents' involvement in the care of their children in the hospital ranged from providing basic care tasks, such as feeding and managing children's emotions during painful procedures, to active participation in providing simple clinical procedures to their children:

"We bring to him food and liquids and things like that" (Mother \#4)

"I play and do games that would keep her quiet. If I do not pay enough attention, she would feel scared. She is scared of injections and doctors." (Mother \#11)

Parents' involvement in the clinical procedures required a form of partnership to develop between the parents and the nurses. The extent to which parents were involved in providing clinical care procedures depended on the parents' competencies in performing the clinical skills:

Interviewer: "To what extent did the nurses rely on you in doing this type of care?"

Mother: "We both did it together. In the beginning, I did not have any clue about all this [clinical care procedures], but when I continued to accompany my daughter, I started to know about injections and fluids and how they are to be given. Sometimes I do not wait for the nurses to take off the IV-tube when the fluids are finished. Though, the nurses stayed around parents who didn't know how [to perform the clinical care procedures], while they relied completely on mothers who could take temperature alone, for example." (Mother \#11)

Parents were involved in performing part of the clinical procedures because of their developed experience with hospital care. Examples of such procedures, as reported by the parents, were 1) measuring and reporting temperature, 2) hanging and monitoring IV fluids or medications, and 3) administering oral medications. Parents were also involved in a few non-clinical procedures that were usually performed by the hospital staff, such as sending blood tubes to the lab and bringing blood units from the blood bank. Parents performed these tasks on the behalf of the hospital staff and healthcare providers as an extension of their parenting role, as well as to shorten the waiting time when the demand was high on hospital staff:

"Yes, I always and immediately take the blood sample to the lab. First, these are our children. Second, why should I wait for the messenger to take the sample and take too long to deliver it? I go myself to the lab and come back faster." (Father \#3)

Aside from networking, parents perceived forms of support from the hospital staff, especially those working at the blood disease centre; overall, parents were satisfied with the quality of care received in the blood disease centre. Parents' satisfaction with care was attributed primarily to their satisfaction with the relationship that they had with the care providers. Parents expressed appreciation to the specialty, individuality, and continuity of care provided by the medical staff:

"The care is constant. Some days we treat him [at the blood disease centre], not just for anemia, but also for his sore throat, for example. We attend the centre because this is a specialized centre and doctors here know better about the 
condition of our children. They know, for example, the importance of doing blood count tests, and if you decide to go somewhere else, you would have to explain about the disease and suffer. Here at the centre, the doctors are specialized and know how to care for our children very well." (Father \#9)

Empathy, humanity, understanding and respect were qualities of health care providers, including doctors and nurses that the parents most appreciated. On the other hand, it was noted that blaming, ordering, and limited engagement with children and parents during care provision, were the qualities of health care providers that parents condemned the most. Parents, in general, were more satisfied with their interactions with physicians than they were with nurses:

"The nurses only do the tests and administer medications, while the doctors are the ones who know her condition and provide guidance and advice about the right thing to do. They prepare you psychologically and provide you relief." (Mother \#2)

In terms of informative support, the level of information parents possessed about SCD was minimal, superficial, general, and most often, inaccurate. The primary sources of the participants' information were their personal experiences with the disease in their children and other children's experience learned through networking from one family to another:

"Well, my knowledge is limited to what I have experienced with my childs treatment." (Mother \#8)

A large share of the parents' description of the disease was about the clinical manifestation of the most common complications of SCD. Knowing when it was necessary to seek medical attention was of particular importance:

Interviewer: What do you know about sickle cell anemia?

Mother: It is pain! And it is very hard to explain how pain feels. As much as the word pain means, it prevents you to sleep day or night. I see my daughter's activity level goes down and she is unable to walk at all, because of the pain in her legs or hands. We try to keep her still.

Interviewer: Where did you get your information from?

Mother: From my experience. I live this sickness.

Interviewer: Who has explained about it?

Mother: No one has. (Mother \#5)

Parents reported that physicians explained the symptoms only during the short time after diagnosis. The participants rarely mentioned nurses, printed materials, and the internet as sources of information. Moreover, according to the reports, parents and/or their children did not appear to receive any structured health education sessions, either formal or informal, from the health care providers.

\section{Discussion}

This study described parents' experiences of caring for their children with SCD, as a chronic illness in childhood, in Jordan. Three themes emerged from 
the interview discussions about parenting children with SCD: 1) the catastrophe, 2) parenting hardship, and 3) networking and support. The results of this study have provided insights into the disease's emotional and social cost on the parents through exploring the parents' everyday strains and challenges while managing the complex demands of caring for their children with SCD. Further, this study has raised several concerns about their needs, the quality of their life, and the overall SCD care services. All of which highlight implications for healthcare providers, particularly nurses and social workers.

The severe emotional impact of the initial SCD diagnosis was central in the parents' conversation. Surprise, shock, guilt, and depression were emotions that parents expressed when they received the initial diagnosis of SCD in their infants [17]. Our study indicated that these emotions continue to be vivid in the parents' memories years after their child's initial diagnosis in infancy. Parents expressed a desire to stop future marriages of couples who were confirmed to be carriers of the SCD trait. This desire is a manifestation of the parents' own guilt and feelings of regret, and an expression of their unspoken desire to avoid the unhappy emotions and subsequent life hardships that came with the SCD diagnosis in their children.

Prior to the SCD diagnosis, parents lacked knowledge about SCD in general, as well as the possibility of carrying the disease trait. They were also unaware of the disease symptoms prior to diagnosis. In agreement with the literature, mothers often had not even heard of SCD and its mode of transmission prior to their child's diagnosis [11]. This lack of awareness was shown to contribute to a delay in diagnosis for children with SCD. Most children in this study were diagnosed with SCD between the mid and the end of infancy, and only after the emergence of symptoms and disease complications. The late diagnosis of SCD, as noted in this study, is an alarming finding because it indicates late or delayed treatment that could have been otherwise received earlier. The results of this study point to the importance of including SCD in premarital genetic testing and counseling, and the implementation of newborns being screened for the disease via national screening programms. This initiative is especially encouraged for high-risk populations. In this study, the delayed SCD diagnosis and limited disease awareness occurred even among high-risk parents, such as those who had relatives with SCD and who were involved in consanguineous marriages. Arab populations have a long tradition of consanguinity, due to socio-cultural factors, specifically first cousin marriages. In many Arab countries, consanguinity may reach $25 \%-30 \%$ of all marriages, a frequency which contributes to the increased rates of inherited genetic disorders [18].

To reduce the rates of genetically transmitted disease, many Mediterranean and Middle Eastern countries have adopted health policies involving Mandatory Premarital Screening and Genetic Counselling (MPSGC) programmes to screen for sexually and genetically transmitted diseases [19]. All parents in this study were married before the MPSGC programme was implemented in Jordan. The 
MPSGC programmes were implemented in 2004 and, as is currently the case in many countries, were mainly focused on thalassemia screening. Premarital screening for SCD was not included in the national MPSGC programmes in Jordan until 2016 [20]. Similar to many countries in the world, SCD is not part of Jordan's National Newborn Screening programme. All of these factors contributed to the lack of knowledge about the disease exhibited by parents in this study, prior to SCD symptoms appearing in their children. Parents' lack of knowledge about SCD, prior to presentation of symptoms in their children, could also be a reflection of the low public awareness in Jordan about genetically transmitted diseases in general, and SCD in particular. A recent study showed that the uptake of genetic testing in Jordan is minimal and directed towards the MPSGC programmes rather than diagnostic or predictive testing [21]. Additionally, misconceptions about premarital and genetic testing have been commonly reported in the literature [22] [23]. All of which foster the need for developing more effective community models for raising public awareness of the disease.

Parents' lives, after the diagnosis of SCD in their children, became difficult. They felt drained by the hardship and struggled with caring for their sick children, especially during the painful vasoocclusive attacks. Admission to the hospital was identified as one of the top stressors experienced by the parents of children with SCD [13]. Previous studies, conducted in diverse countries, have also shown that SCD symptoms, especially higher frequency of painful crises in children, were related to increased caregivers' levels of stress, anxiety, depression, feelings of burden, and emotional distress [6] [13] [24]. The findings of this study send an alarming inquiry about the adequacy of pain care of the children with SCD, which warrant further investigation alongside the quality of life of the SCD children's parents and families. The findings from our study indicate that the family dynamics are seriously challenged by having children with SCD; especially job performance and fulfilling the needs of other siblings; data which are in line with other results within the literature concerning other cultures [12] [13] [14] [15]. All of which highlight the need for social services with community approaches and strategies to promote the health, wellbeing, and quality of life of both parents and children with SCD, in Jordan and worldwide.

The parents in this study viewed their devotion to their children's care and well being at the hospital as an expected part of parenthood. Staying in the hospital and participating in their child's care, required a partnership to develop between the health care providers, particularly the nurses, and parents. A partnership in which families and health care teams share responsibilities of children's health care is the core of family-centred care [25]. Nurses in this study tailored parents' involvement in clinical care, based on each parent's specific competencies. Generally, nurses' trust in parents' competencies was an important element in determining the level to which parents could become involved actively in caring of their hospitalized children. Parents with chronically ill children in particular, were generally allowed to continue providing certain clinical 
procedures in the hospital [26].

However, in this study the partnership appeared more holistic when involving physician-parent relationships, rather than in the nurse-parent relationships. Social and community workers did not show vital role in the parent's conversations. Parents in this study showed more trust and engagement with physicians than they did with nurses. Contrary to their perceptions of the doctors, the parents viewed nurses as task oriented, rather than child or parent oriented. Nurses in this study were reported to be around the parents and children only during routine clinical assessment and for implementing procedures. Although, this finding could be explained by the parents perceived higher social status of doctors over nurses [27]; parents in this study voiced a need for nurses to be more physically present and engage in more communication with both the parents and children. Social-work professionals need to be involved in the care plans of SCD children and their parents according to our study. Community nursing and social work professionals, as tertiary care qualified professionals, have the potential to maximize the wellbeing of the parents of SCD children and their parents by serving as liaisons between the parents and community resources in order to meet the psychosocial and socioeconomic needs of the parents that were highlighted in this study.

The formation of family-family networks during their children's hospital stay is a prominent finding of this study that reflects a cultural feature of Jordan. The parents created networks to fill a void that they felt existed when it came to peer support and to satisfy their need of knowledge about the disease. The parents "lived" their children's experience with SCD and learned from it. However, the parents in this study showed minimal knowledge about the disease.

However, most of the parents' information came from their experience of caring for their children and from other parents, but not from valid sources, such as effective reading materials or structured teaching sessions by competent health care providers. Establishing support groups for children with SCD and their families is strongly recommended. Support groups can strengthen peer support and knowledge of the families; they would provide opportunities for SCD children and their families to engage with each other, as well as with experts, doctors, and nurses. Nurses, according to the results of this study, need to be more family oriented and need to engage more in health education activities with SCD children and their parents.

\section{Conclusion}

Parents of children with sickle cell disease face complex caregiving demands and altered family dynamics that warrant careful assessment and attention by the healthcare providers. There is an overarching need of the family for social support and knowledge. Spiritual and parenthood values have shaped a vast part of the meaning of the parents' experiences. Raising public awareness about SCD and the need to conduct premarital screening for the disease are important for 
allowing informed marriage-related decisions to be made in advance among people intending to create families. Nursing and social-work professionals can play a vital role in developing and implementing a comprehensive model of care with community-based approach and strategies to maximize the wellbeing of SCD children and their parents.

\section{Limitations}

Based on participants' convenience, few interviews were conducted with the children were in the room. Parents may not be completely expressive about the strains and negative impact of caring for their child with their child presence. This factor should be considered in future studies on the topic.

\section{Acknowledgements}

The authors would like to thank all participating parents for their cooperativeness and contribution, without which the study could not have come to a successful conclusion.

\section{Declaration of Conflicting Interests}

This research received no specific grant from any funding agency in the public, commercial, or not-for-profit sectors. There is no conflict of interest to declare.

\section{References}

[1] Piel, F.B., et al. (2013) Global Epidemiology of Sickle Haemoglobin in Neonates: A Contemporary Geostatistical Model-Based Map and Population Estimates. The Lancet, 381, 142-151. https://doi.org/10.1016/S0140-6736(12)61229-X

[2] Ware, R.E., et al. (2017) Sickle Cell Disease. The Lancet, 390, 311-323. https://doi.org/10.1016/S0140-6736(17)30193-9

[3] Yawn, B.P., et al. (2014) Management of Sickle Cell Disease: Summary of the 2014 Evidence-Based Report by Expert Panel Members. JAMA, 312, 1033-1048. https://doi.org/10.1001/jama.2014.10517

[4] Graves, J.K. and Jacob, E. (2014) Pain, Coping, and Sleep in Children and Adolescents With Sickle Cell Disease. Journal of Child \& Adolescent Psychiatric Nursing, 27, 109-120. https://doi.org/10.1111/jcap.12077

[5] Kelly, A.D., et al. (2015) A Controlled Study of Internalizing Symptoms in Older Adolescents with Sickle Cell Disease. Pediatric Blood \& Cancer, 62, 637-642. https://doi.org/10.1002/pbc.25325

[6] Unal, S., et al. (2011) Evaluation of the Psychological Problems in Children with Sickle Cell Anemia and Their Families. Pediatric Hematology and Oncology, 28, 321-328. https://doi.org/10.3109/08880018.2010.540735

[7] Bhatt-Poulose, K., et al. (2016) Increased Rates of Body Dissatisfaction, Depressive Symptoms, and Suicide Attempts in Jamaican Teens with Sickle Cell Disease. Pediatric Blood \& Cancer, 63, 2159-2166. https://doi.org/10.1002/pbc.26091

[8] Bolaños-Meade, J. and Brodsky, R.A. (2014) Blood and Marrow Transplantation for Sickle Cell Disease: Is Less More? Blood Reviews, 28, 243-248.

https://doi.org/10.1016/j.blre.2014.08.001 
[9] Rees, D.C., Williams, T.N. and Gladwin, M.T. (2010) Sickle-Cell Disease. The Lancet, 376, 2018-2031. https://doi.org/10.1016/S0140-6736(10)61029-X

[10] Cousino, M.K. and Hazen, R.A. (2013) Parenting Stress among Caregivers of Children with Chronic Illness: A Systematic Review. Journal of Pediatric Psychology, 38, 809-828. https://doi.org/10.1093/jpepsy/jst049

[11] Burnes, D.P.R., et al. (2008) Mothers Raising Children with Sickle Cell Disease at the Intersection of Race, Gender, and Illness Stigma. Health \& Social Work, 33, 211-220. https://doi.org/10.1093/hsw/33.3.211

[12] Mitchell, M.J., et al. (2007) Parent Perspectives on Pain Management, Coping, and Family Functioning in Pediatric Sickle Cell Disease. Clinical Pediatrics, 46, 311-319. https://doi.org/10.1177/0009922806293985

[13] Wonkam, A., et al. (2014) Psychosocial Burden of Sickle Cell Disease on Parents with an Affected Child in Cameroon. Journal of Genetic Counseling, 23, 192-201. https://doi.org/10.1007/s10897-013-9630-2

[14] Brown, B.J., et al. (2010) Burden of Health-Care of Carers of Children with Sickle Cell Disease in Nigeria. Health \& Social Care in the Community, 18, 289-295. https://doi.org/10.1111/j.1365-2524.2009.00903.x

[15] Jacob, E., Childress, C. and Nathanson, J.D. (2016) Barriers to Care and Quality of Primary Care Services in Children with Sickle Cell Disease. Journal of Advanced Nursing, 72, 1417-1429. https://doi.org/10.1111/jan.12756

[16] Braun, V. and Clarke, V. (2006) Using Thematic Analysis in Psychology. Qualitative Research in Psychology, 3, 77-101. https://doi.org/10.1191/1478088706qp063oa

[17] Chudleigh, J., et al. (2016) Parents' Experiences of Receiving the Initial Positive Newborn Screening (NBS) Result for Cystic Fibrosis and Sickle Cell Disease. Journal of Genetic Counseling, 25, 1215-1226. https://doi.org/10.1007/s10897-016-9959-4

[18] Tadmouri, G.O., et al. (2009) Consanguinity and Reproductive Health among Arabs. Reproductive Health, 6, 17. https://doi.org/10.1186/1742-4755-6-17

[19] Saffi, M. and Howard, N. (2015) Exploring the Effectiveness of Mandatory Premarital Screening and Genetic Counselling Programmes for $\beta$-Thalassaemia in the Middle East: A Scoping Review. Public Health Genomics, 18, 193-203. https://doi.org/10.1159/000430837

[20] Azzeh, L. (2016) Pre-Marital Medical Check up to Test for Sickle-Cell Anaemia. The Jordan Times, Jordan Press Foundation Amman, Jordan.

[21] Ahram, M., et al. (2015) Knowledge, Attitudes, and Practice Regarding Genetic Testing and Genetic Counselors in Jordan: A Population-Based Survey. Journal of Genetic Counseling, 24, 1001-1010. https://doi.org/10.1007/s10897-015-9839-3

[22] Balci, Y.I., et al. (2014) Thalassemia Premarital Screening Program: Public View, What Has Been Done, What Needs to Be Done? Evlilik Öncesi Talasemi Tarama Programı: Halkın Gözünden, Neler Yapılıyor, Neler Yapılmalı? Vol. 24, 247-252.

[23] Alkhaldi, S.M., et al. (2016) Knowledge and Attitudes toward Mandatory Premarital Screening among University Students in North Jordan. Hemoglobin, 40, 118-124. https://doi.org/10.3109/03630269.2015.1135159

[24] Edmond, S.N., et al. (2016) Emotional Distress and Burden among Caregivers of Children with Oncological/Hematological Disorders. Families, Systems \& Health. The Journal of Collaborative Family Health Care, 34, 166-171. https://doi.org/10.1037/fsh0000181

[25] Mikkelsen, G. and Frederiksen, K. (2011) Family-Centred Care of Children in Hos- 
pital-A Concept Analysis. Journal of Advanced Nursing, 67, 1152-1162. https://doi.org/10.1111/j.1365-2648.2010.05574.x

[26] Coyne, I. (2013) Families and Health-Care Professionals' Perspectives and Expectations of Family-Centred Care: Hidden Expectations and Unclear Roles. Health Expectations.

[27] Shoqirat, N. (2015) "We Are Nurses, They Are Doctors": Barriers to Nurses' Roles in Pain Management Following Surgery in Jordan. International Journal of Nursing Practice, 21, 200-206. https://doi.org/10.1111/ijn.12240 